\title{
A SINGLE HPLC-DAD METHOD FOR SIMULTANEOUS ANALYSIS OF PARACETAMOL, PHENYLEPHRINE, CAFFEINE AND LEVOCETIRIZINE IN BULK POWDER AND TABLET FORMULATION: APPLICATION TO IN- VITRO DISSOLUTION STUDIES
}

\author{
ANIL P. DEWANI*, SRDHANJALI PATRA2 \\ 1 . \\ University department of pharmaceutical sciences, Utkal University, Bhubaneshwar, India
}

\begin{abstract}
Present work describes development and validation of HPLC-DAD method for the analysis of a complex mixture consisting phenylephrine hydrochloride (PHE), paracetamol (PAR), caffeine (CAF) and levocetirizine (LEV). Chromatographic separation was achieved using a Kinetex-C18 column involving gradient elution, the mobile phase composed of $10 \mathrm{mM}$ phosphate buffer $(\mathrm{pH} 3.3$ ) and methanol. The three step gradient program started with step-1 initially with $2 \%$ (by volume) methanol and $98 \%$ phosphate buffer ( $\mathrm{pH} 3.3$ ) for first 5 minutes. In step- 2 methanol concentration changed linearly to $80 \%$ in next 12 minutes the analysis was concluded by step-3 changing methanol to $2 \%$ in next 8 minutes. The method was linear in concentration ranges of 50 to $200 \%$ of labeled claims with $\mathrm{r}^{2}$ near to 1 . Developed method proved to be precise for inter and intra-day studies the \%RSD values were $<2$, accuracy studies by standard addition at 80,100 and $120 \%$ levels resulted in recoveries of standard near to $100 \%$. The method was selective with no interferences from placebo; robustness of method was proved by no significant alteration in system suitability parameters. The LOD values for PHE, PAR, CAF and LEV were $0.13,0.51,0.05$ and 0.05 and LOQ were $0.39,1.53$, 0.15 and 0.15 respectively. The study concluded a validated HPLC method for analysis of complex mixture consisting PHE, PAR, CAF and LEV in bulk, tablet and dissolution samples in simulated gastric fluid (SGF).
\end{abstract}

Keywords: phenylephrine, paracetamol, caffeine, levocetirizine, HPLC-DAD.

\section{INTRODUCTION:}

Phenylephrine (PHE) chemically is (1R)-1-(3hydroxy-phenyl)-2(methylamino) ethanol hydrochloride and is used as sympathomimetic (descongestants), Paracetamol (PAR) is analgesic and antipyretic chemically it is N-(4-hydroxyphenyl) acetamide. Caffeine (CAF) chemically is (1,3,7-trimethyl-1H-purine-2,6(3H,7H)-dione and acts as a central nervous system stimulant. levocetirizine (LEV) provides prompt relief of itchy watery eyes, runny nose, sneezing, itching of the nose or throat due to respiratory allergies chemically it is chemically $( \pm)$-[2-[4-[(4-chlorophenyl)phenylmethyl] 1-piperazinyl]ethoxy]acetic acid dihydrochloride. Structural formulas of PHE, PAR, CAF, and LEV are given in figure 1.

\begin{tabular}{l}
\hline Paracetamol (PAR) \\
Hydrochloride (PHE) \\
Caffeine (CAF) \\
$\begin{array}{l}\text { L e v o c e t i r i z i n e } \\
\text { Dihydrochloride (LEV) }\end{array}$
\end{tabular}

Figure 1: The structures of Paracetamol (PAR), Phenylephrine hydrochloride (PHE), Caffeine (CAF) and Levocetirizine (LEV).

The mixture of four is recommended to relieve symptoms such as nasal and sinus congestion, allergic symptoms of the nose or throat due to upper respiratory tract allergies and sinus pain associated with headache. The multidrug mixture is also used as an adjunct with antibacterials in sinusitis, tonsillitis, and otitis media.

The tablet contains a variable amount of all ingredients due to their recommended pharmacological dose; the tablet contains $10 \mathrm{mg}$ of phenylephrine hydrochloride, $500 \mathrm{mg}$ of paracetamol, $30 \mathrm{mg}$ caffeine and $2.5 \mathrm{mg}$ levocetirizine. This variable amount of ingredients in such a multi-drug formulation makes the process of analysis difficult. Moreover, the active compounds have very different polarity and therefore chromatographic behavior. So far no single HPLC method is reported for quantification of mentioned analytes in a mixture. Literatures revels number of analytical methods published for PHE, PAR, CAF and LEV with some other drug combinations.

Methods for paracetamol and its combinations in pharmaceuticals or in biological fluids have been reported. Paracetamol has been determined in combination with other drugs using titrimetry(1,2), voltammetry (3), fluorimetry (4), colorimetry (5), UV-spectrophotometry (6), quantitative thinlayer chromatography (TLC) (7), high-performance liquid chromatography (HPLC) (8-13) and gas chromatography (GC) (14) in pharmaceutical formulations.

An HPLC method for phenylepherine in combination with Chlorpheniramine Maleate has been reported (15).

Caffeine has been analyzed in combination with some other active agents by variety of analytical methods such as spectrophotometry (16), HPLC (17) and HPTLC (18).

Levocetirizine the levo isomer of cetirizine has been reported for analytical methods such as HPLC for estimations in formulations (19), spectrophotometry (21), Capillary zone electrophoresis (22) a stability indicating assay method is also reported $(23,24)$.

To our knowledge, the methods described in the literature do not cover the analysis of four analytes PHE, PAR, CAF and LEV in a pharmaceutical mixture in the form of tablet formulation. Therefore, the objective of this work was to develop a single separation method for quantifying these four analytes which are present in variable concentrations in tablet dosage form.

Within this context, a simple and rapid HPLC-DAD method for determination of these drugs in tablet formulation and in dissolution samples is reported. The method was validated for linearity, system suitability, selectivity, sensitivity (LOD and LOQ), accuracy, precision and robustness; the method proved to be successful and was applied to the analysis of commercial product containing these active ingredients. Further the method was extended for estimation of this mixture in dissolution media composed of simulated gastrointestinal fluid and successfully marked the release kinetics of conventional tablet in the media.

\section{EXPERIMENTAL}

\subsection{Chemicals and Reagents}

Working standards of pharmaceutical grade phenylephrine hydrochloride, paracetamol, caffeine and levocetirizine were obtained as generous gifts from Leben pharmaceuticals (Akola Maharashtra, India). They were used without further purification. Fixed dose combination tablet Sinarest-LP $\mathbb{B}$ (Centaur 
Pharmaceuticals Ltd) containing $10 \mathrm{mg}$ phenylephrine hydrochloride, $500 \mathrm{mg}$ Paracetamol, $30 \mathrm{mg}$ caffeine and 2.5 levocetirizine was purchased from local market, Yavatmal, Maharashtra, India. All the chemicals were of HPLC grade, purchased from Merck Chemicals, India. Water used was double distilled and filtered through $0.45 \mu \mathrm{m}$ filter.

\subsection{Instrumentation}

HPLC analyses were performed on a Waters liquid chromatography equipped with a model 600 solvent pump, a 996 Photo Diode Array Detector,and a 515 Autosampler. Empower v.2 Software (Waters Spa, Milford, MA, USA) was used for data acquisition and recording chromatograms. Effective separation was achieved on a reverse phase Kinetex C18 packing column $(4.6 \mathrm{~mm} \times 250 \mathrm{~mm}, 5 \mu \mathrm{m}$ particle size; Phenomenex, Torrance, CA, USA) builded with core shell technology.

\subsection{Preparation of standard stock and sample solution}

\subsubsection{Preparation of standard stock solution:}

Preliminarily sample preparation was done in acetonitrile taking accurately weighed quantity of $10 \mathrm{mg}$ of PHE, $500 \mathrm{mg}$ of PAR, $30 \mathrm{mg}$ of CAF and $2.5 \mathrm{mg}$ of LEV transferred to $100 \mathrm{ml}$ volumetric flasks separately to give stock solutions of $100 \mu \mathrm{g} / \mathrm{ml}$ of PHE, $5000 \mu \mathrm{g} / \mathrm{ml}$ of PAR, $300 \mu \mathrm{g} / \mathrm{ml}$ of CAF and $25 \mu \mathrm{g} / \mathrm{ml}$ of LEV.

\subsubsection{Preparation of mixed standard solution:}

A mixed standard solution was prepared from these stock solutions by transferring $10 \mathrm{~mL}$ of each of the stock solution to a $100 \mathrm{~mL}$ volumetric flask and diluting with methanol to get a solution of $10,500,30$ and $2.5 \mu \mathrm{g} / \mathrm{ml}$ of PHE, PAR, CAF and LEV respectively.

\subsubsection{Preparation of sample solution of tablet:}

For preparation of sample solution of pharmaceutical mixture twenty

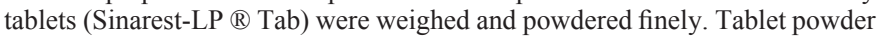
equivalent to $10 \mathrm{mg}$ of PHE, $500 \mathrm{mg}$ of PAR, $30 \mathrm{mg}$ of CAF and $2.5 \mathrm{mg}$ of LEV was transferred to a $100 \mathrm{ml}$ volumetric flask and dissolved in methanol up to the mark. The solution was ultra sonicated for $15 \mathrm{~min}$ and filtered through 0.45 micron membrane filter. The solutions were further diluted to obtain resultant concentration of $10 \mu \mathrm{g} / \mathrm{ml}$ of PHE, $500 \mu \mathrm{g} / \mathrm{ml}$ of PAR, $30 \mu \mathrm{g} / \mathrm{ml}$ of CAF and $2.5 \mu \mathrm{g} / \mathrm{ml}$ of LEV the resultant mixture was subjected to HPLC analysis in developed chromatographic conditions.

\subsection{Chromatographic Conditions}

Initial trials were carried by an isocratic mode of analysis using mixture of phosphate buffer and organic phase acetonitrile and methanol. Looking to the variability in polarities trials were initiated on reverse phase Kinetex C-18 column $(150 \mathrm{~mm} \times 4.5 \mathrm{~mm}$ i.d., particle size $5 \mu)$ from Phenomenex. Experiments concluded lack of resolution of complex mixture of four analytes using isocratic approach of analysis. The gradient mode was opted comprising buffer and methanol as organic phase. Mobile phase composed of $10 \mathrm{mM}$ phosphate buffer ( $\mathrm{pH} 3.3)$ and methanol. The elution was a three step gradient elution program with flow of $1 \mathrm{ml} / \mathrm{min}$ throughout the method, step-1 started initially with $2 \%$ (by volume) methanol and $98 \%$ phosphate buffer for 5 minutes, methanol concentration changed linearly to $80 \%$ in next 12 minutes followed by final step-3 reverting methanol concentration back to $2 \%$ and phosphate buffer $98 \%$ in last 8 minutes thus concluding the method in total run time of 25 minutes. The eluants were monitored at $230 \mathrm{~nm}$. The mobile phase was filtered through 0.45 micron membrane filter and degassed before use. The injection volume was $20 \mu$ and all analyses were performed at ambient temperature. Figure 2 shows the chromatogram for standard mixture obtained through the optimized variables in accordance with the features described above.

\section{RESULTS AND DISCUSSION}

\subsection{Method Development and Optimization of chromatographic} conditions:

The development of the method was based on the experience obtained from the HPLC method previously developed for the analysis of mixture of analytes comprising phenylephrine, paracetamol, caffeine and chlorpheniramine maleate (Dewani et.al 2012) (25) by authors. Experiments previously suggest use of C-18 stationary phases of $(150 \mathrm{~mm} \times 4.5 \mathrm{~mm}$ i.d., particle size $5 \mu \mathrm{m})$ hence for the study an reverse phase Phenomenex Kinetex-C18 column was utilized. For the separation of all the four analytes in mixture the composition and $\mathrm{pH}$ of mobile phase was varied. Parameters such as mobile phase composition of buffer at different $\mathrm{pH}$ values were exhaustively studied so as to achieve a reasonable degree of separation of analytes. Several binary or ternary eluants were experimented using different proportions of solvent such as acetonitrile, methanol, water and buffer at different $\mathrm{pH}$ conditions. Initially isocratic mode of separation was experimented and was found insufficient to resolve the mixture with good peak characters hence gradient mode was selected so as to achieve separation of analytes with good peak characters. The optimized gradient program was varied by changing the organic phase in programmed steps. Initially a four step gradient program gave good separation of all the four analytes with total run time of 30 minutes, in order to reduce the total run time it was optimized further. The final optimized gradient program was a three step gradient program having total run time of 25 min thus reducing the total run time by 5 minutes. The mean retention time of four analytes was PHE 3.4, PAR 11.03, CAF 15.30 and LEV 17.9 min respectively. Peak identification was done by injecting individual analyte in developed chromatographic conditions. A value of 1.5 for resolution implies a complete separation of any two consecutive peaks $[26,27]$. Resolution was calculated between the adjacent peaks of PHE, PAR, CAF and LEV which was $>1.5$ indicating an adequate degree of resolution. System suitability parameters were recorded for the optimized chromatographic conditions and presented in table 1.

3.2. Method Validation

3.2.1. Specificity studies:

Specificity studies proved absence of any interference in the presence of placebo (diluents i.e. acetonitrile) at the retention time of analytes (PHE, PAR, CAF and LEV eluted at retention times 3.4, 11.03, 15.30 and $17.9 \mathrm{~min}$ respectively) as no other peaks were observed. Also no interferences were observed from excipients present in formulation. A typical chromatogram of placebo is presented by figure 3 .

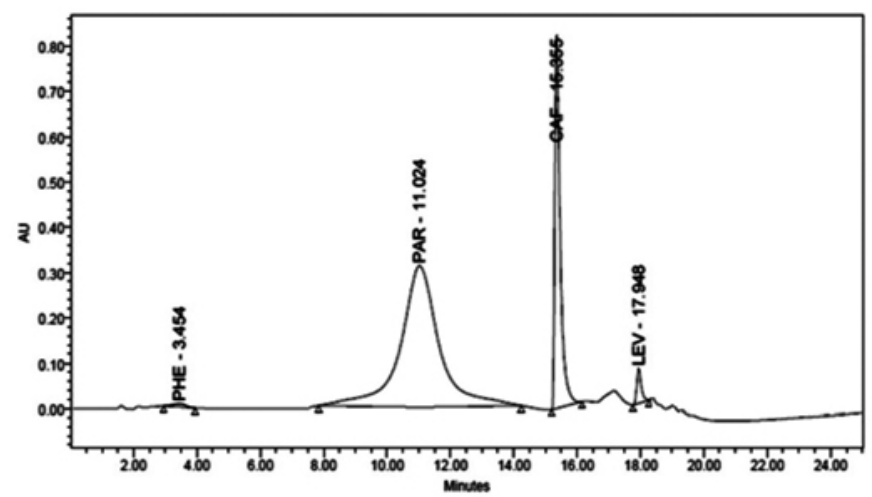

Figure 2: HPLC chromatogram obtained during simultaneous separation of PHE, PAR, CAF and LEV.

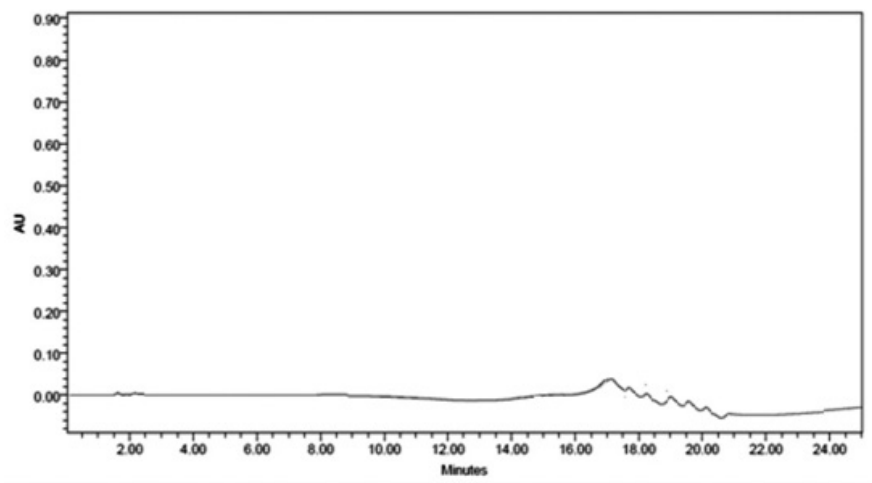

Figure 3: Chromatogram showing a placebo runs in developed chromatographic conditions.

\subsubsection{Linearity and Range:}

For linearity, an external method was used for the simultaneous determination of selected three ingredients. Seven stage concentrations were chosen ranging from $50 \%$ to $200 \%$ of the target analyte concentrations in formulations. So the linearity dilution concentrations were PHE 2.5, 4, 5, 6, 7.5, 9 and $10 \mu \mathrm{g} / \mathrm{ml}$, PAR 250, 400, 500, 600, 750, 900 and $1000 \mu \mathrm{g} / \mathrm{ml}$, CAF 15 , $24,30,36,45,54$ and $60 \mu \mathrm{g} / \mathrm{ml}$ and LEV $1.25,2,2.5,3,3.75,4.5$ and $5 \mu \mathrm{g} / \mathrm{ml}$. All the solutions were prepared by diluting in acetonitrile. Each concentration of standard mixture solutions was injected five times $(n=5)$ and the mean 
value of peak area was taken for the calibration curve. Calibration graph was obtained by plotting peak area versus concentration of standard drugs. The linear regression equations for PHE, PAR, CAF and LEV were found to be $\mathrm{y}=29098 \mathrm{x}+9750, \mathrm{y}=29098 \mathrm{x}+9750, \mathrm{y}=31115 \mathrm{x}+27542$ and $\mathrm{y}=24445 \mathrm{x}+$ 78560 respectively. The regression coefficient values $\left(\mathrm{R}^{2}\right)$ were found to be $0.999,0.997,0.998$ and 0.994 respectively indicating an acceptable degree of linearity. The results showed that an excellent correlation existed between peak area and concentration of drug within the selected concentration range. The results confirmed the linearity and the reproducibility of the assay method as an acceptable fit of the linear regression was demonstrated by construction of residual plots which showed a perfect agreement between observed recoveries and predicted recoveries. The significance between the observed and predicted recoveries was established by applying F-test and student's t-test the regression characteristics of the proposed HPLC method are given in table 2 .

Table 1: System Suitability parameters.

\begin{tabular}{|c|c|c|c|c|}
\hline \multirow{2}{*}{$\begin{array}{c}\text { Mean } \pm \% \text { RSD } \\
(\mathbf{n}=\mathbf{5})\end{array}$} & \multicolumn{4}{|c|}{ Eluted peaks } \\
\hline & PHE (1) & PAR (2) & CAF (3) & LEV (4) \\
\hline$t_{r}(\min ) \pm \% R S D$ & $3.412 \pm 1.07$ & $11.035 \pm 1.2$ & $15.36 \pm 1.3$ & $17.95 \pm 1.1$ \\
\hline $\mathbf{k}^{\prime} \pm \%$ RSD & $1.15 \pm 1.1$ & $5.89 \pm 1.5$ & $8.6 \pm 1.8$ & $10.21 \pm 1.6$ \\
\hline $\mathbf{N} \pm \%$ RSD & $2161.50 \pm 1.9$ & $3152.50 \pm 1.9$ & $8650.90 \pm 1.8$ & $3110.60 \pm 1.2$ \\
\hline $\mathrm{h} \pm \%$ RSD & $0.08 \pm 1.2$ & $0.03 \pm 1.1$ & $0.08 \pm 1.5$ & $0.11 \pm 1.1$ \\
\hline$T_{f} \pm \%$ RSD & $1.26 \pm 1.3$ & $1.8 \pm 1.20$ & $1.21 \pm 1.10$ & $0.94 \pm 1.8$ \\
\hline \multirow[t]{3}{*}{ Peak area $\pm \%$ RSD } & $192651.30 \pm 1.8$ & $28770313 \pm 1.6$ & $9676186.6 \pm 1.8$ & $744890 \pm 1.5$ \\
\hline & \multicolumn{4}{|c|}{ Eluted Peak pairs } \\
\hline & \multicolumn{2}{|c|}{$1 \& 2$} & $2 \& 3$ & $3 \& 4$ \\
\hline $\mathbf{R}_{\mathrm{s}} \pm \% \mathbf{R S D}$ & \multicolumn{2}{|c|}{$6.09 \pm 1.8$} & $3.76 \pm 1.9$ & $3.23 \pm 1.8$ \\
\hline$\alpha \pm \%$ RSD & \multicolumn{2}{|c|}{$5.12 \pm 1.1$} & $1.46 \pm 1.2$ & $1.18 \pm 1.1$ \\
\hline
\end{tabular}

$\mathrm{t}_{\mathrm{r}}$ - retention time, $\mathrm{k}^{\prime}-$ Capacity factor, $\mathrm{N}-$ Plate number, $\mathrm{h}-$ HETP (height equivalent to theoretical plates) $\mathrm{T}_{\mathrm{f}}-$ Peak asymmetry factor, $\mathrm{R}_{\mathrm{s}}-\mathrm{Resolution}_{\mathrm{s}}$ $\alpha-$ Selectivity (Separation factor).

Table 2: Linearity parameters and statistical analysis.

\begin{tabular}{|l|l|l|l|l|}
\hline \multicolumn{1}{|c|}{ Linearity parameters } & \multicolumn{1}{c|}{ PHE } & \multicolumn{1}{c|}{ PAR } & \multicolumn{1}{c|}{ CAF } & \multicolumn{1}{c|}{ LEV } \\
\hline Range $(\mu \mathrm{g} / \mathrm{ml})$ & 2.5 to 10 & 250 to 750 & 15 to 45 & 1.25 to 3.75 \\
\hline Slope & $29098.55 \pm 28.50$ & $29098.76 \pm 29.90$ & $31115.66 \pm 22.80$ & $24445.66 \pm 12.25$ \\
\hline Intercept & $9750.35 \pm 19.15$ & $9750.2 \pm 10.49$ & $27542.32 \pm 9.03$ & $78560.55 \pm 12.74$ \\
\hline Regression coefficient $\left(\mathrm{R}^{2}\right)$ & 0.999 & 0.997 & 0.998 & 0.994 \\
\hline$F$-Test & $1.0001(6.38)^{\mathrm{a}}$ & $1.002(6.38)^{\mathrm{a}}$ & $1.001(6.38)^{\mathrm{a}}$ & $1.005(6.38)^{\mathrm{a}}$ \\
\hline$t$-test $(\mathrm{p}$-value $)$ & $0.5(2.13)^{\mathrm{a}}$ & $0.50(2.13)^{\mathrm{a}}$ & $0.49(2.13)^{\mathrm{a}}$ & $0.50(2.13)^{\mathrm{a}}$ \\
\hline$L O D(\mu \mathrm{g} / \mathrm{ml})$ & 0.13 & 0.51 & 0.05 & 0.05 \\
\hline$L O Q(\mu \mathrm{g} / \mathrm{ml})$ & 0.39 & 1.53 & 0.15 & 0.15 \\
\hline
\end{tabular}

Values are reported as mean \pm s.d. of five calibration curves generated on five consecutive days

$(n=5)$. Eight concentrations in the linearity range were evenly distributed.

${ }^{a}$ The values in parenthesis are the theoretical values of f-test and student's t-test at 95\% confidence level.

\subsubsection{Accuracy:}

The accuracy of an analytical method expresses the closeness of agreement between the value, which is accepted reference value, and the value found. Accuracy studies were done by standard addition method. Accuracy was expressed as \% recovery of the standard spiked to previously analyzed test samples of tablet. The active ingredients were spiked in previously analyzed tablet powder sample at different concentration levels viz. 80\%,100\%, and $120 \%$ each of the labeled claim and injected in developed chromatographic conditions in triplicate. The percentage recoveries were calculated from the slope and Y-intercept of the calibration curve. The mean recovery values of PHE, PAR, CAF and LEV were excellent in all the three selected concentration levels. The recovery data's for accuracy studies are shown in table 3 .

\subsubsection{Precision:}

The precision of an analytical method is the closeness of replicate results obtained from analysis of the same homogeneous sample. Precision was determined through the estimate of the relative standard deviation (RSD) values for three concentration levels (50,80 and $150 \%)$. Precision studies for repeatability or intra-day precision were done by performing nine analysis at different time intervals on same day $(3 \times 3=9)$ at three concentration levels. Interday precision studies were done by injecting the prepared standard solution of three concentration levels for every day up to three consecutive days. \%RSD values were measured during each studies indication of low values of $\%$ RSD showed that the method is precise within the acceptance limit of $\pm 2 \%$ RSD. The intra and inter-day variability or precision data are given in table 4 . The results indicated good precision of the developed. 
Table 3: Recovery data for accuracy studies

\begin{tabular}{|c|c|c|c|c|}
\hline \multirow[b]{2}{*}{ Recovery level } & \multirow[b]{2}{*}{ Std. added to placebo } & \multirow[b]{2}{*}{$\begin{array}{c}\text { Amount added } \\
(\mathrm{mg})\end{array}$} & \multirow[b]{2}{*}{$\begin{array}{c}\text { Mean } \underset{ }{\text { recovery }}(\mathrm{mg}) \pm \\
(\mathrm{n}=6)\end{array}$} & \multirow[b]{2}{*}{ Mean \% Recovery } \\
\hline & & & & \\
\hline \multirow{4}{*}{$80 \%$} & PHE & 8 & $7.95 \pm 1.3$ & 99.37 \\
\hline & PAR & 400 & $398 \pm 1.9$ & 99.50 \\
\hline & CAF & 24 & $24.1 \pm 1.7$ & 100.41 \\
\hline & LEV & 2 & $1.97 \pm 1.9$ & 98.50 \\
\hline \multirow{4}{*}{$100 \%$} & PHE & 10 & $9.9 \pm 1.9$ & 99.00 \\
\hline & PAR & 500 & $493 \pm 1.9$ & 98.60 \\
\hline & CAF & 30 & $29.8 \pm 1.7$ & 99.33 \\
\hline & LEV & 2.5 & $2.55 \pm 1.5$ & 102.00 \\
\hline \multirow{4}{*}{$120 \%$} & PHE & 12 & $11.80 \pm 1.6$ & 99.33 \\
\hline & PAR & 600 & $590.00 \pm 1.8$ & 98.33 \\
\hline & CAF & 36 & $35.6 \pm 1.8$ & 98.88 \\
\hline & LEV & 3 & $2.95 \pm 1.8$ & 98.33 \\
\hline
\end{tabular}

Table 4: Precision Data of Intra-Day and Inter-Day Assay ( $n=6)$.

\begin{tabular}{|c|c|c|c|}
\hline \multirow{2}{*}{ Concentration $\boldsymbol{\mu g} / \mathbf{m l}$} & \multicolumn{2}{|c|}{$\begin{array}{c}\text { Measured mean concentration, \%RSD } \\
\text { precision (n=6) }\end{array}$} & $\begin{array}{c}\text { Intra-day precision } \\
(\mathbf{n}=\mathbf{6})\end{array}$ \\
\hline \multicolumn{3}{|c|}{ PHE } \\
\hline $50 \%$ & 2.5 & $2.4,1.6$ & $2.45,1.2$ \\
\hline $80 \%$ & 4.0 & $4.1,1.2$ & $3.9,1.5$ \\
\hline $150 \%$ & 7.5 & $7.6,1.3$ & $7.55,1.2$ \\
\hline \multicolumn{3}{|c|}{ PAR } \\
\hline $50 \%$ & 250 & $245.2,1.9$ & $246.1,1.1$ \\
\hline $80 \%$ & 400 & $392.2,1.8$ & $391.1,1.5$ \\
\hline $150 \%$ & 750 & $738.1,1.2$ & $739.5,1.2$ \\
\hline \multicolumn{5}{|c|}{} & CAF \\
\hline $50 \%$ & 15 & $14.6,1.8$ & $14.2,1.4$ \\
\hline $80 \%$ & 30 & $29.1,1.7$ & $28.9,1.8$ \\
\hline $150 \%$ & 45 & $44.2,1.7$ & $44.1,1.1$ \\
\hline \multicolumn{2}{|c|}{} & LEV \\
\hline $50 \%$ & 1.25 & $1.22,1.9$ & $1.20,1.5$ \\
\hline $80 \%$ & 2.00 & $1.92,1.5$ & $1.90,1.4$ \\
\hline $150 \%$ & 3.75 & $3.70,1.2$ & $3.67,1.2$ \\
\hline
\end{tabular}

\subsubsection{LOD and LOQ for method}

LOD and LOQ were determined to mark the sensitivity of developed method. The LOD and LOQ for PHE, PAR, CAF and LEV were determined at a signal-to-noise ratio of $3: 1$ and 10:1, respectively, by injecting a series of dilute solutions with known concentrations. The LODs for PHE, PAR, CAF and LEV were $0.13,0.03,0.12$ and $0.15 \mu \mathrm{g} / \mathrm{ml}$ respectively whereas LOQs were $0.39,0.09,0.36$ and $0.45 \mu \mathrm{g} / \mathrm{ml}$ respectively. The values of LOD and LOQ indicated the method sensitivity. The values of LOD and LOQ are summarized in table 2 .

\subsubsection{Robustness studies:}

The robustness of a method is the ability to remain unaffected by small changes in chromatographic parameters. The experimental conditions were purposely altered and the chromatographic resolution of PHE, PAR, CAF and LEV was assessed. The chromatographic parameters included variation of flow rate second deliberate change was made by change in $\mathrm{pH}$ and third was deliberate change in detection wavelength. To study the effect of flow rate on system suitability parameters $\pm 10 \%$ (approx) change on either side of actual flow rate was made i.e. from $1.0 \mathrm{~mL} / \mathrm{min}$ to $0.9 \mathrm{~mL} / \mathrm{min}$ and $1.1 \mathrm{~mL} / \mathrm{min}$ (figure 4), while other conditions were held constant. For experiment to study effect of $\mathrm{pH}$ on system suitability parameters change in $\mathrm{pH}$ of \pm 0.1 units on either side of actual $\mathrm{pH}$ of buffer was made i.e. from 3.3 to 3.2 and 3.4 while other chromatographic conditions were kept constant (figure 5). For variation of detecting wavelength change in detecting wavelength of $\pm 5 \mathrm{~nm}$ was made and system suitability parameters were recorded (figure 6). All the robustness studies were carried using a mix standard having resultant concentration of 10 $\mu \mathrm{g} / \mathrm{ml}$ of PHE, $500 \mu \mathrm{g} / \mathrm{ml}$ of PAR, $30 \mu \mathrm{g} / \mathrm{ml}$ of CAF and $2.5 \mu \mathrm{g} / \mathrm{ml}$ of LEV. The system suitability parameters considered for deliberate changes were \%RSD of peak areas, mean tailing factor and mean retention time. 


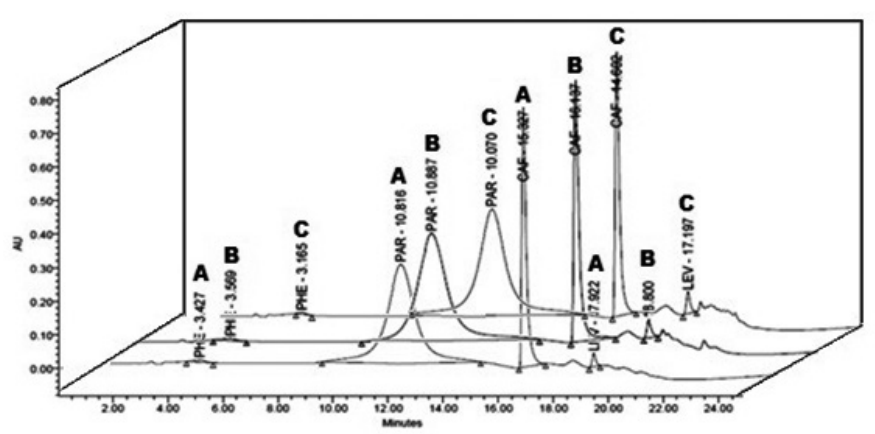

Figure 4: Chromatograms for robustness studies for delibarate change in flow rate.

A: Flow rate of $1 \mathrm{ml} / \mathrm{min}$, B: Flow rate of $0.9 \mathrm{ml} / \mathrm{min}$ and C: Flow rate of $1.1 \mathrm{ml} / \mathrm{min}$

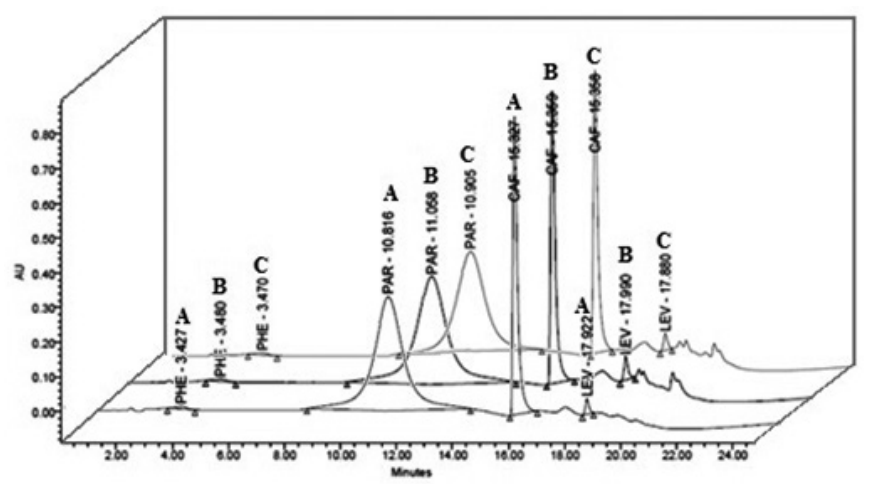

Figure 5: Chromatograms for robustness studies for delibarate change in $\mathrm{pH}$ of buffer.

A: Buffer pH 3.3, B: Buffer pH 3.2 and C: Buffer $\mathrm{pH}$ 3.4.

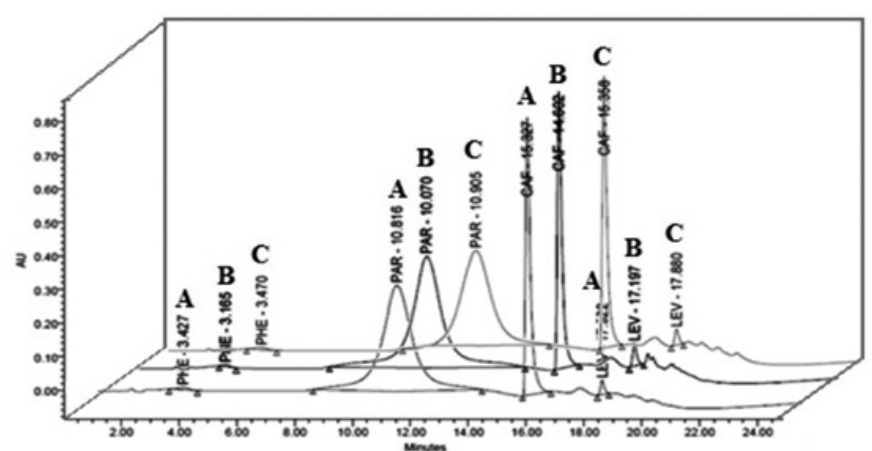

Figure 6: Chromatograms for robustness studies for delibarate change in detection wavelength.

A: Detection wavelength $230 \mathrm{~nm}, \mathrm{~B}$ : Detection wavelength $228 \mathrm{~nm}$ and C: Detection wavelength $232 \mathrm{~nm}$.

\subsubsection{Analysis of formulation:}

The developed method was successfully applied to analyze PHE, PAR, $\mathrm{CAF}$ and LEV in marketed tablet formulation. The amounts recovered were expressed as a percentage of the label claim. Analysis of marketed tablet

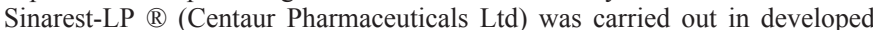
chromatographic conditions. No interferences of excipients were observed in analysis, a representative chromatogram for analysis of tablet formulation is shown in figure 7 . The mean percentage recovery of drug contents of tablets obtained by the proposed method was noted. The percentage recovery found were $98.60 \%$ for PHE, $99.97 \%$ for PAR, $99.53 \%$ CAF, and $100.24 \%$ LEV. The results are given in the table 5. Satisfactory results were obtained for subjecting the marketed formulation to developed HPLC method.

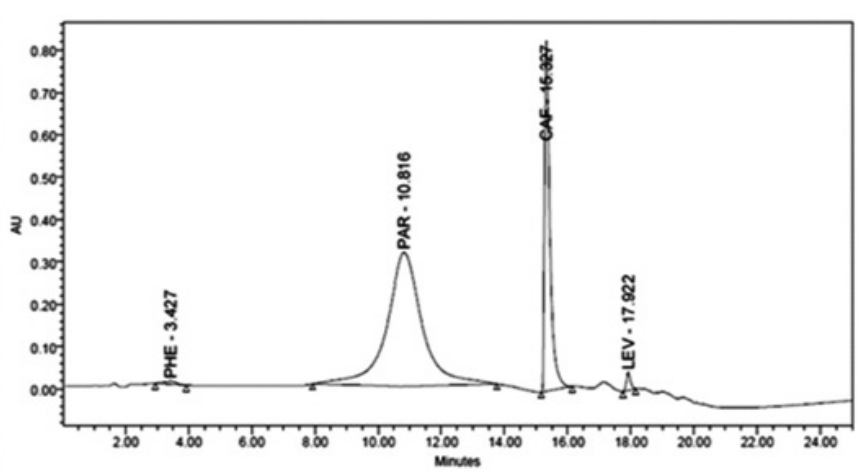

Figure 7: Chromatogram for marketed preperation.

Table 5: Results for assay of marketed formulation

\begin{tabular}{|c|c|c|c|c|}
\hline $\begin{array}{c}\text { Commercial } \\
\text { formulation }\end{array}$ & Ingredients & $\begin{array}{c}\text { Labeled } \\
\text { amount (mg) }\end{array}$ & $\begin{array}{c}\text { Amount } \\
\text { found (mg) }\end{array}$ & $\begin{array}{c}\text { Found } \\
\mathbf{\%}\end{array}$ \\
\hline \multirow{3}{*}{$\begin{array}{c}\text { Sinarest- } \\
\text { LP ® }\end{array}$} & PHE & 10 & 9.86 & 98.60 \\
\cline { 2 - 5 } & PAR & 500 & 499.88 & 99.97 \\
\cline { 2 - 5 } & CAF & 30 & 29.86 & 99.53 \\
\cline { 2 - 5 } & LEV & 2.5 & 2.506 & 100.24 \\
\hline
\end{tabular}

3.2.8 Analysis of dissolution media (Release kinetics studies)

The developed and validated HPLC method was also extended for application to study release kinetics of marketed formulation in simulated gastric fluid (SGF) in dissolution study samples. As the combination consisted of four drugs the study was undertaken to mark any drug interaction during release in gastric conditions. The marketed preparation Sinarest-LP $\mathbb{B}($ Centaur Pharmaceuticals Ltd) was a conventional tablet and hence was subjected to dissolution studies in SGF using USP apparatus paddle type maintained at $50 \mathrm{rpm}$ at $37 \pm 5^{\circ} \mathrm{C}$, the samples were withdrawn at interval of time diluted appropriately and subjected to chromatographic analysis with developed and validated HPLC method. The cumulative percentage of drug released versus time profile showed that more than $90 \%$ of all the drugs were released in simulated gastric fluid (SGF) within $30 \mathrm{~min}$, at $50 \mathrm{rpm}, 37 \pm 5^{\circ} \mathrm{C}$ by USP apparatus paddle type. A graph representing release against time is represented in figure 8 . The study revealed no interaction of all four drug candidates with each other in SGF and moreover no interferences of SGF were observed in process of analysis hence marking the successful application of developed HPLC method for release kinetics studies.

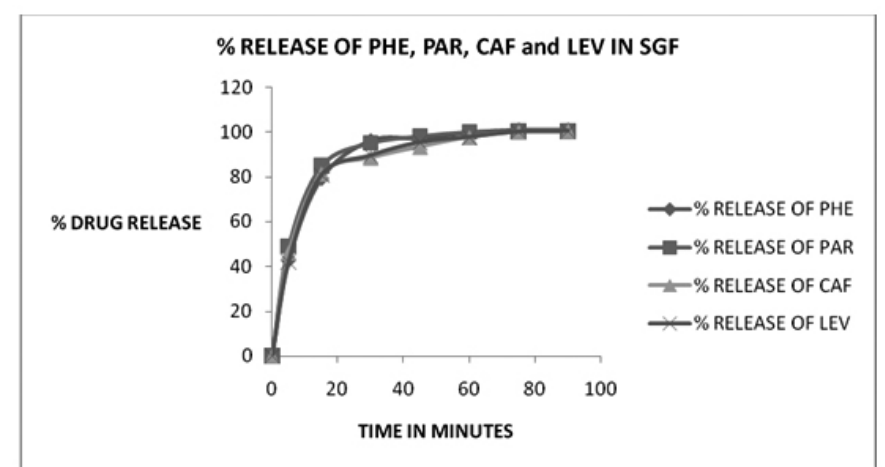

Figure 8: Release kineitics of PHE,PAR, CAF and LEV tablet in SGF

\section{CONCLUSION}

In this study, a validated simple and reliable HPLC-DAD procedure was described for the assay of a complex multi drug combination consisting of PHE, PAR, CAF and LEV which is indicated for the treatment of allergic symptoms of the nose or throat due to upper respiratory tract allergies associated with headache. To our present knowledge, no attempts have yet been made to assay this multidrug mixture by any analytical methodology. All the four analytes 
(PHE, PAR, CAF and LEV) were successfully resolved and quantified using a Reverse phase Phenomenex Kinetex-C18 column in a relatively short run time with the last analyte eluting at 17.9 minutes the gradient program contributed total run time of 25 minutes. Reliability was guaranteed as validation experiments proved that the HPLC method is linear in the proposed working range as well as accurate, precise and specific. The good recovery percentage of tablet forms suggests that the excipients have no interference in the determination. The RSD (\%) was also less than 2 showing a high degree of precision of the method. The proposed method was also found to be robust with respect to flow rate, $\mathrm{pH}$ of mobile phase and detecting wavelength hence it can be recommended for the routine quality control of the studied drugs, either in bulk form or in their combination formulated in some other dosage form.

\section{ACKNOWLEDGMEN}

The authors are grateful to Leben Labs (Akola, Nagpur) for providing gift samples of Paracetamol, Caffeine, Phenylephrine Hydrochloride and Levocetirizine dihydrochloride. Authors also thankful to management and Dr. A.V.Chandewar, principal of P.W.College of pharmacy, Yavatmal for providing timely support for the research work.

\section{REFERENCES}

1. British Pharmacopoeia CD 1998, version 2, The Stationery Office Ltd., Norwich, 1998.

2. European Pharmacopoeia 1997, third edition, pp. 748-749, Convention on the Elaboration of a European Parmacopoeia (European Treaty Series No. 50), Strasbourg, 1996.

3. S. Saeed and S. Reyhaneh-Sadat. International Journal of Electrochemistry., 10 (2011).

4. T. Hossein and H. Yahya. Asian Journal of Biochemical and Pharmaceutical Research. 2(1), 684-689, (2011)

5. F. Shihana, D. Dissanayake, P. Dargan, and A.A. Dawson. Clin Toxicol (Phila). 48(1): 42-46, (2010).

6. M. Ghulam, A.K. Shujaat, S. Arham, M. Arshad, B.A. Muhammad Hassham Hassan, F. Kalsoom, S.M. Nadia and H. Izhar. Scientific Research and Essays. 6(2): 417-421, (2011)

7. A.S. Atul, M.S. Afsar and J.S. Sanjay. Eurasian Journal of Analytical Chemistry. 3(2): 258-267, (2008).

8. M.E. El-Kommos, N.A. Mohamed, A.F.A. Hakiem. Journal of Liquid Chromatography \& Related Technologies. 35(15): 2188-2202, (2012).

9. V.P. Godse, M.N. Deodhar, A.V. Bhosale, R.A. Sonawane, P.S. Sakpal, D.D. Borkar and Y.S. Bafana. Asian J. Research Chem. 2(1): 37-40, (2009).

10. J.T. Franeta, D. Agbaba, S. Eric, S. Pavkov, M. Aleksic, and S. Vladimirov. Farmaco. 57(9): 709-713, (2002).

11. Y.M. Issa, M.E.M. Hassouna, and A.G. Zayed. Journal of Liquid Chromatography \& Related Technologies. 35(15), 2148-2161, (2012).

12. R. Gopinath, S. Rajan, S.N. Meyyanathan, N. Krishnaveni and B. Suresh. Indian Jour. of pharma. sciences. 69(1), 137-140, (2007).

13. B. Olmo, A. García, A. Marín, and C. Barbas. J. Chromatogr. B. 817(2), 159-161, (2005)

14. T. Belal, T. Awad and C.R. Clark. J Chromatogr. Sci. 47(10), 849-54, (2009).

15. M. Mukesh, R. Richa, G. Vertika, K. Dharmendra, K. Amrendra, G. Anand, and S. Ranjit. Pharmacie globale International journal of comprehensive pharmacy. 5(5):1-4, (2010).

16. D. Kuldeep, K. Ritu, K. Prachi, K. Sunil and P. Pratik. International Journal of Pharmacy and Pharmaceutical Sciences. 3(3), 170-174, (2011).

17. R.P. Viswanath, R.M. Useni, B. Varaprasad, and P.A. Somasekhar. Journal of pharmacy research. 4(4), 1225-1227, (2011).

18. H. Misra, D. Mehta, B.K. Mehta, M. Soni, and D.C. Jain. International journal of green pharmacy. 3(1), 47-51, (2009).

19. M. Maithani, R. Raturi, V. Gautam, D. Kumar, A. Gaurav and R. Singh. International Journal of Comprehensive Pharmacy. 1(2): 1-3, (2010).

20. B.S. Nagaralli, J. Seetharamappa, B.G. Gowda, and M.B. Melwanki. J Chromatogr-B Analyt Technol Biomed Life Sci. 798(1), 49-54, (2003).

21. N.M. Bhatia, S.K. Ganbavale and H.N. More. Asian Journal of Pharmaceutics. 2(3), 159-162, (2008).

22. S. Azhagvuel and R. Sekar. Journal of Pharmaceutical and Biomedical Analysis. 43(3), 873-878, (2007).
23. G.M. Hadada, S. Emarab and M.M. Waleed. Talanta. 79: 1360-1367, (2009).

24. M.I. Khan, G. Murtaza, S. Awan, M. Iqbal, M.K. Waqas, A. Rasool, U. Fatima, M.H. Hassan Bin Asad, A. Kahlid, F. Usman, Q. Najam-us Saqib, S.A. Khan, K. Farzana, S. Mahmood. and I. Hussain. African Journal of Pharmacy and Pharmacology. 5(2), 143-149, (2011).

25. A.P. Dewani, B.B. Barik, V.D. Chipde, R.L. Bakal, A.V. Chandewar and S.K. Kanungo. Arabian journal of chemistry. 7, 811-816, (2014).

26. The British Pharmacopoeia, Her Majesty's Stationery Office, London, 2010, 765-766, 1666-1669, 1802-1803, 3001-3002, 3048-3049.

27. International Conference Harmonisation (ICH); Validation of Analytical Procedures:

Methodology, Q2B. 1995 (CPMP/ICH/281/95). 